\title{
Comparative in vitro studies of antiglycemic potentials and molecular docking of Ageratum conyzoides L. and Phyllanthus amarus L. methanolic extracts
}

\author{
Babatunde Joseph Oso ${ }^{1}$ (I) Ige Francis Olaoye ${ }^{1}$ (I)
}

Received: 19 December 2019 / Accepted: 17 February 2020 / Published online: 12 March 2020

(c) Springer Nature Switzerland AG 2020

\begin{abstract}
These in vitro studies investigated the comparative antiglycemic properties and molecular docking of the methanolic extracts of dried leaves of Ageratum conyzoides L. and Phyllanthus amarus L. in an attempt to explore natural products that could be useful in preventing secondary complications that could arise from hyperglycaemia. The methanolic crude extracts of dried leaves of $A$. conyzoides (CEA) and $P$. amarus (CEP) were partitioned into $n$-butanol and aqueous extracts and glycation inhibitory potentials were investigated. The result reveals that CEA and CEP exhibited highest glycemic inhibitory potential on the activities of a-amylase, a-glucosidase and sucrase investigated. The molecular docking was done on reported identified compounds in A. conyzoides and P. amarus with a-amylase (1SMD), sucrase-isomaltase (3LPO) and a-glucosidase (3WY1). Methanol crude extracts exhibited the highest inhibitory effect with the lowest IC $\mathrm{C}_{50}$ values of $(78.00 \pm 1.73,77.00 \pm 1.16),(62.67 \pm 1.45,57.67 \pm 0.88)$ and $(89.67 \pm 3.48,95.33 \pm 2.60) \mu \mathrm{g} / \mathrm{mL}$ respectively for $1 \mathrm{SMD}$, $3 \mathrm{LPO}$ and $3 \mathrm{WY} 1$. The molecular docking analysis depicted that phytol had the best docking binding energy for the three enzymes and oxazolone and 9,12,15-octadecatrienoic acid showed best affinity for 1SMD and 3LPO while none for 3 WY1. Crude and butanol partitioned extracts of both plants had a significant $(p<0.05)$ inhibition on glucose-induced albumin glycation, thiol oxidation and $\beta$-amyeloid aggregation. This study provides evidence suggesting that methanolic crude extracts of both plants could be used in the prevention of diabetes secondary complications.
\end{abstract}

Keywords CEA · CEP · Antiglycation · Antiglycemia · Molecular docking

\section{Introduction}

Diabetes mellitus (DM) is one of the most deadly diseases in the world; its rate coupled with its complications increases with time in every part of the world [1]. This is a metabolic disorder that result from excessive accumulation of glucose in the blood due to either deficiency in insulin synthesis or defects in insulin receptors. In adult, type II Diabetes mellitus is more common compared to type I Diabetes mellitus and its expected to reach 366 million cases in the year 2030 [2]. Type II Diabetes Mellitus (T2DM) is a common disorder of glucose metabolism and has been linked to insulin resistance and high calorie diets thus elevating the postprandial glucose level [3]. Different carbohydrate hydrolyzing enzymes such as a-glucosidase, amylase and sucrase in the brush border of small intestine can be inhibited through regular consumption of the antihyperglycemic drugs e.g. acarbose has been reported as one of the current management strategy for diabetes based on the reduction of glucose level [4]. This inhibition of the enzymes slow down the process of carbohydrate digestion and absorption, which in turn delay glucose absorption and hinder postprandial plasma glucose increase [5]. Nijpels et al. [6] reported that

Ige Francis Olaoye, igeolarinoye@gmail.com | 'Department of Biological Sciences, College of Natural and Applied Sciences, McPherson University, Seriki Sotayo, Ogun, Nigeria. 
daily consumption of acarbose for three years reduced the risk of developing type II diabetes by $6 \%$ compared to the control.

Sometimes accumulation of amyloid, protein glycation and reduction of thiol protein could result as secondary complication of the elevated blood glucose [7]. Secondary complications in diabetic patients and failure or damage of multiple organs were due to delayed hyperglycemia [8]. Acute complications resulting from free radicals formation through glucose oxidation, non-enzymatic glycation of proteins cause lipid and protein metabolic mutation and more continual complications such as retinopathy, cataracts, atherosclerosis, neuropathy, aging and many more due to Advance Glycation End Products AGEs [9].

Systemic oxidative stress resulting from hyperglycemia due to imbalance between antioxidant and reactive oxygen specie (ROS) in favour of ROS causes an increase in insulin resistance and $\beta$-cell dysfunction, thus promoting the devlopment of type 2 diabetes mellitus [10-12]. Cellular damage caused by ROS is prevented by removing excess ROS via an endogenous antioxidant mechanisms such as catalase, superoxide dismutase, and the peroxidase-glutathione system [13]. Thiols are compounds with a free sulfhydryl (R-SH) moiety occurring in the form of proteins containing one or more free cysteine groups or low molecular-weight compounds (e.g. glutathione) in cells and extracellular fluids which is oxidized and transformed to disulfide [14]. The formed disulfide moiety is expected to be related to some secondary complications of diabetes mellitus [15]. However, the gastrointestinal side effects of known carbohydrate hydrolyzing enzyme inhibitors such as acarbose, miglitol and voglibose and inefficiency of the endogenous defense system to scavenge free radicals rest on natural exogenous antioxidants. Antioxidants from plant source are known to reduce oxidative stress thus, phytomedicines are sought as possible alternatives or adjuncts [16]. This present in vitro study investigated the carbohydrate hydrolyzing enzymes inhibitory potential, amyloid aggregation inhibition, non-enzymatic glycation inhibitory properties and thiol containing protein of different extracts of Ageratum conyzoides and $P$. amarus leaves for the prevention of secondary complications in DM and binding behavior of reported isolated compounds.

\section{Materials and methods}

\subsection{Material}

Absolute methanol, butanol, ethanol, congo red, dinitrosalicylic acid, para-nitrophenylglucopyranoside, trichloroacetic acid, bovine serum albumin, 5, 5'-dithiobis (2-nitrobenzoic acid) were obtained from JHD in China.
Other reagents were of analytical grade and were prepared with distilled water.

\subsection{Method}

\subsubsection{Samples preparation}

Fresh leaves of $A$. conyzoides and $P$. amarus were air-dried at room temperature of $29 \pm 1{ }^{\circ} \mathrm{C}$. The samples were authenticated at the Department of Biological Sciences Herbarium, McPherson University, Nigeria with voucher numbers McUBHA0001 and McUBHP0005 for A. conyzoides and $P$. amarus respectively. The dried leaves of $A$. conyzoides and $P$. amarus were pulverized and $10 \mathrm{~g}$ of each pulverized samples were extracted with $100 \mathrm{~mL}$ of methanol at room temperature of $29 \pm 1{ }^{\circ} \mathrm{C}$ for $24 \mathrm{~h}$ and later filtered. Two-third of the crude extracts were partitioned repeatedly inside a separating funnel into an aqueousextract and n-butanol extract. The crude extracts and the partitioned extracts were used as the corresponding extracts for the subsequent analyses.

\subsubsection{Preparation of the crude a-glucosidase and sucrase solution}

The mucosa of the small intestine of rats sacrificed under light anaesthesia was carefully scraped off with a glass slide, homogenized in cold sodium phosphate buffer $(\mathrm{pH}$ 6.8) and centrifuged at $4{ }^{\circ} \mathrm{C}$ for $20 \mathrm{~min}$ at $650 \times g$. The clear solution was used as source of crude of a-glucosidase and sucrase solutions [17].

\subsubsection{Inhibition of the a-amylase activity}

The determination was carried out according to the method described by Bernfeld [18]. In a test tube containing $1.0 \mathrm{~mL}$ of $2 \mathrm{mM}$ phosphate buffer $(\mathrm{pH} 6.9), 0.1 \mathrm{~mL}$ of each extract was incubated with $0.05 \mathrm{~mL}$ of a-amylase solution for $20 \mathrm{~min}$. Precisely $0.1 \mathrm{~mL}$ of $1.0 \%$ of freshly prepared starch solution was subsequently added and allowed to stand for $5 \mathrm{~min}$. Next, $0.5 \mathrm{~mL}$ of dinitrosalicylic acid reagent was and held in boiling water for $5 \mathrm{~min}$. The solution was subsequently cooled and the absorption was measured at $540 \mathrm{~nm}$. The result was expressed in $\mathrm{IC}_{50}(\mu \mathrm{g} /$ $\mathrm{mL}$ ) calculated as the concentration needed for inhibition of $50 \%$ of a-amylase activity.

\subsubsection{Inhibition a-glucosidase activity}

The determination was carried out based on the method described by Kim et al. [19]. In a test tube containing $1.0 \mathrm{~mL}$ of $2 \mathrm{mM}$ phosphate buffer $(\mathrm{pH} 6.9), 0.1 \mathrm{~mL}$ of each extract was incubated with $0.1 \mathrm{~mL}$ of mucosa 
solution for $20 \mathrm{~min}$. Subsequently, $0.1 \mathrm{~mL}$ of $3 \mathrm{mM}$ of para-nitrophenylglucopyranoside prepared in $20 \mathrm{mM}$ phosphate buffer ( $\mathrm{pH}$ 6.9) was added and allowed to stand for $15 \mathrm{~min}$. Then, $0.5 \mathrm{~mL}$ of $5.0 \%$ sodium carbonate was added, incubated for $90 \mathrm{~min}$ and the absorbance was read at $450 \mathrm{~nm}$. The result was expressed as the concentration of inhibition required to inhibit $50 \%$ of a-glucosidase activity $\left[\mathrm{IC}_{50}(\mu \mathrm{g} / \mathrm{mL})\right]$.

\subsubsection{Assay of sucrase inhibitory activity}

The determination was carried out according to the method described by Honda and Hara [20]. In a test tube containing $1.0 \mathrm{~mL}$ of $2 \mathrm{mM}$ phosphate buffer $(\mathrm{pH}$ 6.9), $0.1 \mathrm{~mL}$ of each extract was incubated with $0.1 \mathrm{~mL}$ of mucosal solution for $20 \mathrm{~min}$. Afterward, $0.1 \mathrm{~mL}$ of $60 \mathrm{mM}$ sucrose solution was added and incubated for $5 \mathrm{~min}$. Then, $0.5 \mathrm{~mL}$ of dinitrosalicylic acid reagent was transferred into the test tube and incubated in boiling water for $5 \mathrm{~min}$. The test tube was cooled and the optical density at $540 \mathrm{~nm}$ was read. The percentage inhibition of sucrase activity was calculated and the result was expressed in $\mathrm{IC}_{50}(\mu \mathrm{g} / \mathrm{mL})$ as the inhibition concentration required to inhibit $50 \%$ of sucrase activity.

\subsubsection{In vitro glycation of albumin}

The preparation of glycated albumin was carried out according to the procedure defined by Safari et al. [21] with slight modifications. The solution contained bovine serum albumin $(0.1 \mathrm{~g} / \mathrm{mL})$ prepared in $0.1 \mathrm{M}$ phosphate buffer ( $\mathrm{pH} 7.4$ ) containing $0.01 \%$ sodium azide, $\mathrm{D}$-glucose $(10 \mathrm{mg} / \mathrm{mL})$ and the extract combined in ratio 3:2:1 and incubated for $72 \mathrm{~h}$.

\subsubsection{Estimation of anti-glycation capacity}

The determination was carried out colometrically using the method described by Furth [22]. In a test tube containing $1.0 \mathrm{~mL}$ of glycated sample, $0.5 \mathrm{~mL}$ of $10 \%$ trichloroacetic acid was added. For $5 \mathrm{~min}$, the solution was centrifuged at $650 \mathrm{~g}$. Then, $1.0 \mathrm{~mL}$ of phosphate buffer and $0.5 \mathrm{~mL}$ of $0.3 \mathrm{~N}$ oxalic acids were added to the sediment and boiled for $60 \mathrm{~min}$. The solution was cooled and $0.5 \mathrm{~mL}$ of $10 \%$ trichloroacetic acid solution and $0.5 \mathrm{~mL}$ $0.05 \mathrm{M}$ thiobarbituric acid were added and boiledfor $10 \mathrm{~min}$. The solution was centrifuged at $650 \times \mathrm{g}$ and the absorbance of the supernatant was read at $443 \mathrm{~nm}$. The result was reported as percentage inhibition.

\subsubsection{Determination of inhibition of glycation-induced oxidation of protein thiol groups}

The determination was carried out colometrically using the method described by Ellman [23]. Accurately, $1.0 \mathrm{~mL}$

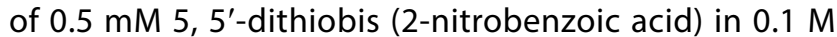
Phosphate buffer ( $\mathrm{pH} 7.4$ ) was transferred into a test tube containing $1.0 \mathrm{~mL}$ of glycated sample and incubated at room temperature of $29^{\circ} \mathrm{C}$ for $15 \mathrm{~min}$. The absorbance at $412 \mathrm{~nm}$ was measured. The thiol group concentration was calculated using molar extinction $=1.34 \times 10^{4} \mathrm{M}^{-1} \mathrm{~cm}^{-1}$. The findings were documented as a protein of $\mathrm{nmol} / \mathrm{mg}$ (Figs. 1, 2, 3, 4).

\subsubsection{Determination of inhibition of protein aggregation}

The determination was carried out colometrically using the method described by Klunk et al. [24]. Precisely, $0.1 \mathrm{~mL}$ of $1 \%$ Congo red prepared in phosphate buffer with $10 \%$ ethanol was added to a test tube containing $1.0 \mathrm{~mL}$ of glycated sample. The solution was incubated for $30 \mathrm{~min}$, absorbance was measured at $530 \mathrm{~nm}$ and the percentage of the results was reported.

\subsubsection{Statistical analysis}

The results obtained were expressed as mean \pm standard deviation of three determination and analyzed using one-way variance analysis (ANOVA) for mean differences between different extracts followed by Duncan multiple range test for post hoc correlation at $p<0.05$.

\subsubsection{Molecular docking}

In association with in vitro antiglycemia activity, it is useful to carry out molecular studies to predict the binding affinity at the active site of the selected hydrolases. The docked selected compounds with carbohydrate hydrolyzing enzymes were the major compounds identified as an active agents in Ageratum conyzoides $[25,26]$ and in $P$. amarus [27] and the 3D SDF format structures were obtained from PubChem data base. The compounds were neophytadiene (PubChem CID: 10446), caryophyllene (PubChem CID: 5354499), phytol (PubChem CID: 5280435), 9,12,15-octadecatrienoic acid (PubChem CID: 860), 9,17-octadecadienal (PubChem CID: 5365667) and oxazolone (PubChem CID: 1712094) while the 3D structure targeted enzymes were obtained as from RCSB Protein Data Base (PDB) as 1SMD, 3LPO and 3WY1 for a-amylase, sucrose-isomaltase and $\beta$-glucosidase respectively. All the compounds and the enzymes were autodocked into pdbqt format and the affinity energy $(\mathrm{kcal} / \mathrm{mol})$ between compound and enzyme were measured using 


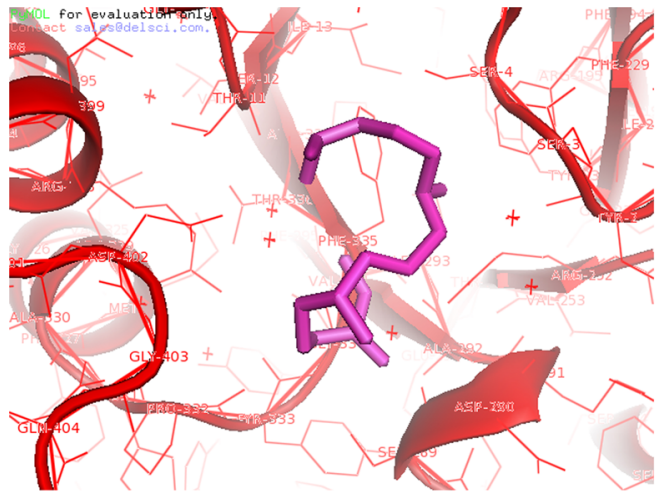

(Ai)

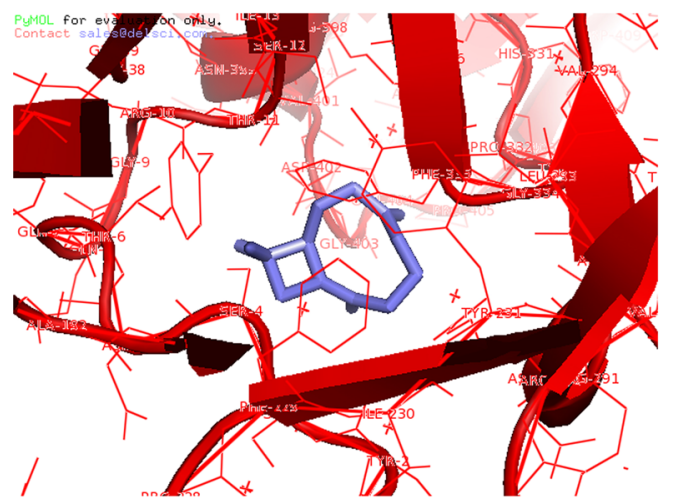

(Aiii)

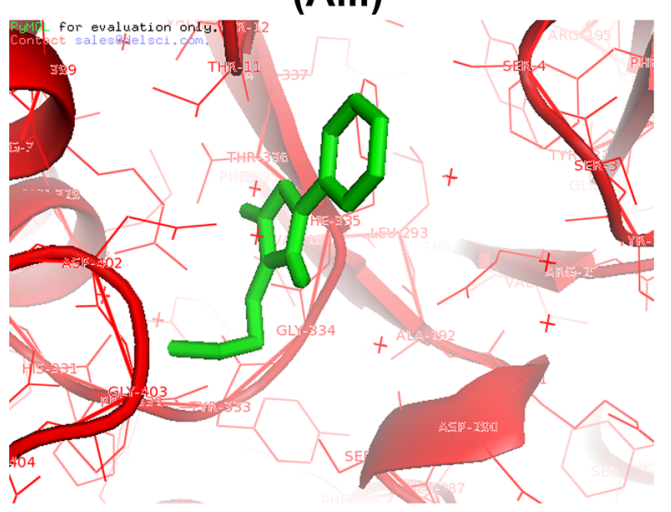

(Av)

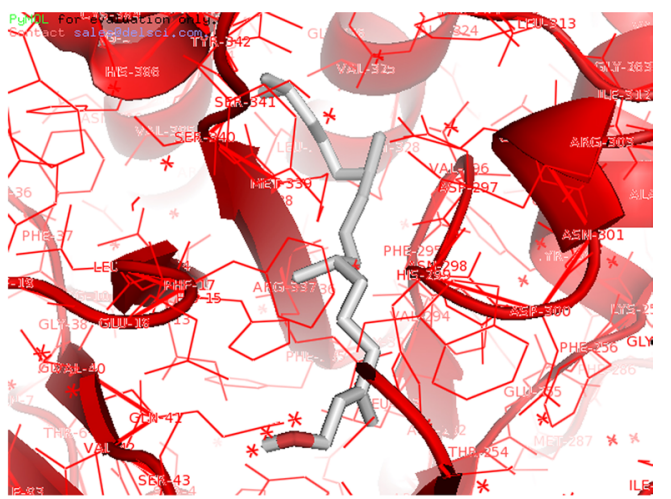

(Aii)

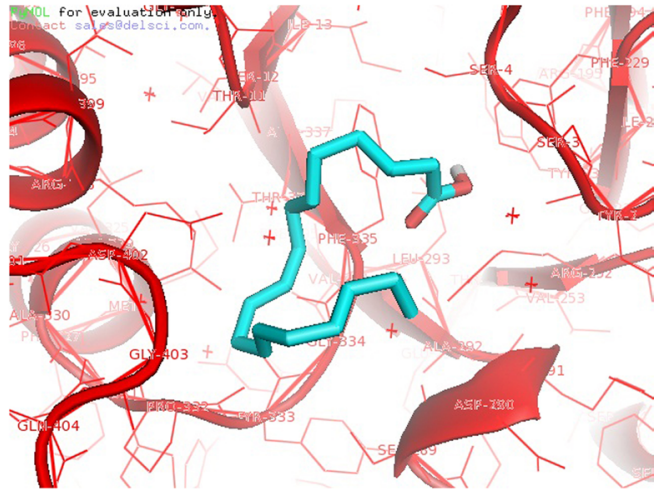

(Aiv)

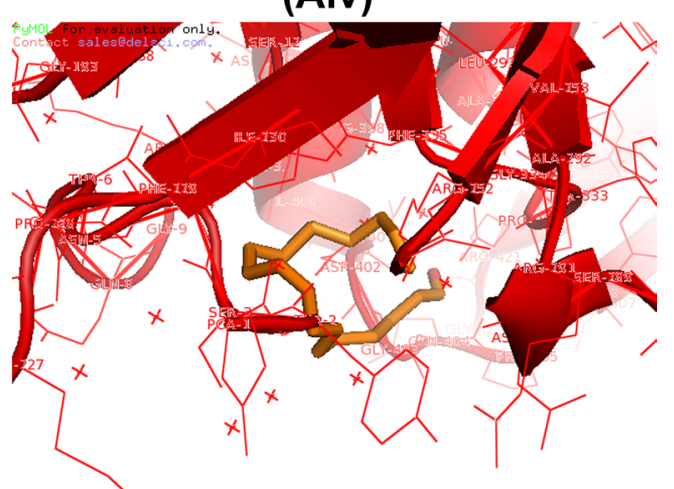

(Avi)

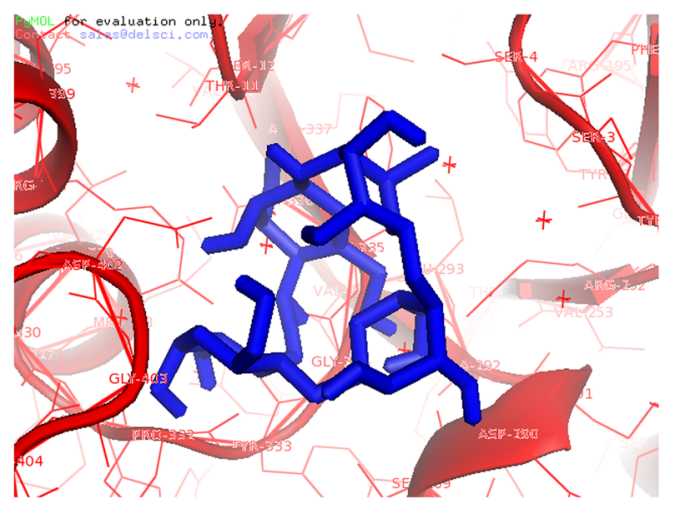

(Avii) 
4Fig. 1 Molecular docking of compounds with enzyme Ai a-amylase (1SMD) and neophytadiene (10446), Aii a-amylase (1SMD) and phytol (5280435), Aiii a-amylase (1SMD) and caryophyllene (5354499), Aiv a-amylase (1SMD) and 9,12,15-octadecatrienoic acid (860), Av a-amylase (1SMD) and oxazolone (1712094), Avi a-amylase (1SMD) and 9,17-octadecadienal (5365667) and Avii a-amylase (1SMD) and acarbose (41774)

PyRx-Python Prescription 0.8 and visisualized using PyMOL ver. 1.leval. The affinity results of the compounds were compared to those of acarbose (PubChem CID: 41774) with the enzymes.

\section{Results}

The inhibitory potential of the extracts varied towards the three selected carbohydrate hydrolases (Table 1). The results depicted that no significant difference $(p<0.05)$ between the butanol extracts and the metanolic extracts of the plants but are significantly different $(p<0.05)$ from the aqueous extracts of the plants towards the $a$-amylase activity. Also, butanol and methanol extracts possessed higher inhibition than the aqueous extracts; although the methanolic extracts had the best inhibitory potential. There is significant difference $(p<0.05)$ among the extracts towards sucrase activity except for both aqueous and butanol extracts of $A$. conyzoides leaves with methanolic crude extract of $P$. amarus (CEP) possessing the highest inhibition (57.67 \pm 0.88$)$. Similarly no significant difference $(p<0.05)$ in inhibition towards a-glucosidase between aqueous residual extract of $P$. amarus (AREP) and butanol partitioned extract of $P$. amarus (BPEP) and between methanolic crude extract of $A$. conyzoides (CEA) and CEP which are significantly difference $(p<0.05)$ from aqueous residual extract of $A$. conyzoides (AREA) and butanol partitioned extract of $A$. conyzoides (BPEA). However, none of the extracts from both plants possessed inhibitory potential more than acrabose towards the three carbohydrate hydrolyzing enzymes.

The visual screening results of selected reported compounds present in both plants with the selected carbohydrate hydrolases revealed the binding energies (Table 2). The docking report showed that all the compounds docked towards a-amylase (1SMD) possessed higher affinity than acarbose except caryophyllene while none has higher affinity than acarbose towards sucraseisomaltase (3LPO) and a-glucosidase (3WY1). Also, phytol (5280435) has the highest biniding energy towards the three enzymes compared to other two compounds from A. conyzoides and none of the compounds from P. amarus docked with a-glucosidase (3WY1) possessed any binding energy.
The antiglycation properties of the extracts were evaluated through the assessment of the inhibitory potential of the extracts against albumin glycation, thiol groups oxidation, and $\beta$-amyloid aggregation (Table 3 ). There were significant differences in the inhibitory effect of the extracts against glucose-induced albumin glycation thiol groups oxidation and $\beta$-amyloid aggregation. The albumin glycation inhibitory potential of BPEA and CEA were statistically $(p<0.05)$ different from that of BPEP and CEP respectively but with values higher than what is obtained from AREA and AREP and AREA had the least. Also, extracts of $P$. amarus were not only statistically different from their corresponding $A$. conyznoides extracts but higher than their values. There is a significant decrease in the thiol groups oxidation in the albumin-glycated sample when incubated with the extracts but no significant difference $(p<0.05)$ between BPEA and CEA and their corresponding BPEP and CEP with CEP being the highest. However the aqueous extracts exhibited less inhibitory effect with AREA being the least. It was also observed that inhibition of $\beta$-amyloid aggregation followed the same trend and CEP had the highest inhibition of $\beta$-amyloid aggregation $(28.00 \pm 0.58 \%)$ while AREA had the least inhibition of $\beta$-amyloid aggregation (6.67 \pm 0.33$)$.

\section{Discussion}

Plant species investigated for antioxidant activity are known to exhibit antidiabetic effect. It has been estimated that more than 400 herbal or plant-derived products are used for the management of T2DM across the globe [28]. The hypoglycemic effect of some plant extracts has been confirmed in human and animal models of T2DM [29]. The WHO Expert Committee on diabetes recommended that medicinal plants should be investigated further [28]. A. conyzoides, a family of asteraceae with an annual weed of $80-90 \mathrm{~cm}$ in height has been reported to exhibit antioxidant property [30]. Also, the P. amarus of the family Euphorbiaceae contains compounds like alkaloids, flavonoids, lignans, phenols and terpenes which have been shown to interact with most key enzymes such as amylase, glucosidase [31].

The results depicted that the crude extracts of the plants exhibited highest inhibitory potential towards the three hydrolases investigated with no significant difference $(p<0.05)$ from each other except for sucrase while the aqueous extracts had the least.

The reported percentage inhibitory potential was presumed to be the relative extracts/acarbose-induced reduction in the activities of the hydrolases with respect to the corresponding controls (without an extract or acarbose). Also, the inhibitory potential of the CE from the plants 
Fig. 2 Molecular docking of compounds with enzyme $\mathbf{A i}$ sucrose-isomaltase (3LPO) and neophytadiene (10446), Aii sucrose-isomaltase (3LPO) and phytol (5280435), Aiii sucrose-isomaltase (3LPO) and caryophyllene (5354499), Aiv sucrose-isomaltase (3LPO) and 9,12,15-octadecatrienoic acid (860), Av sucrose-isomaltase (3LPO) and oxazolone (1712094), Avi sucrose-isomaltase (3LPO) and 9,17-octadecadienal (5365667) and Avii sucrose-isomaltase (3LPO) and acarbose (41774)
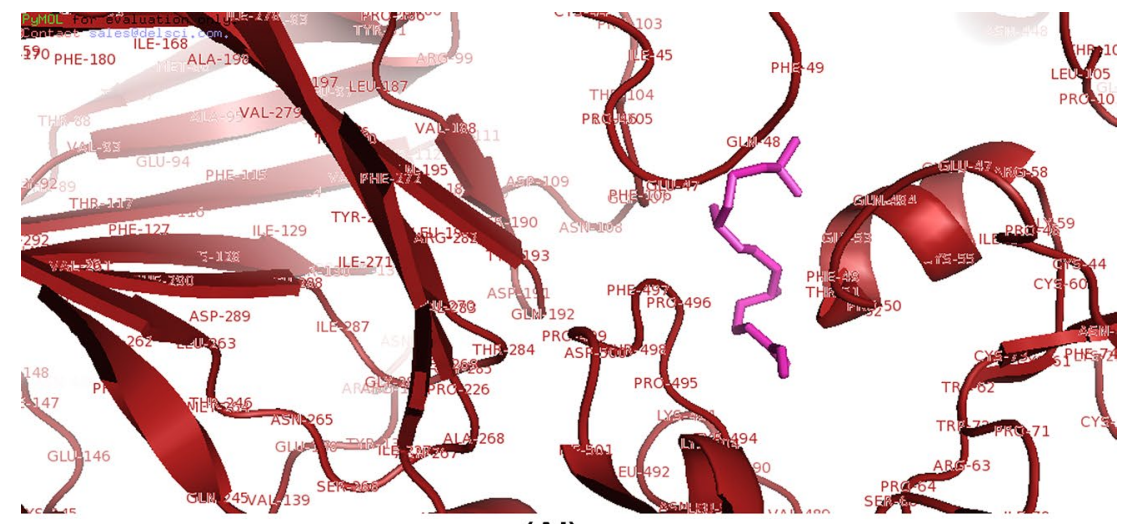

(Ai)

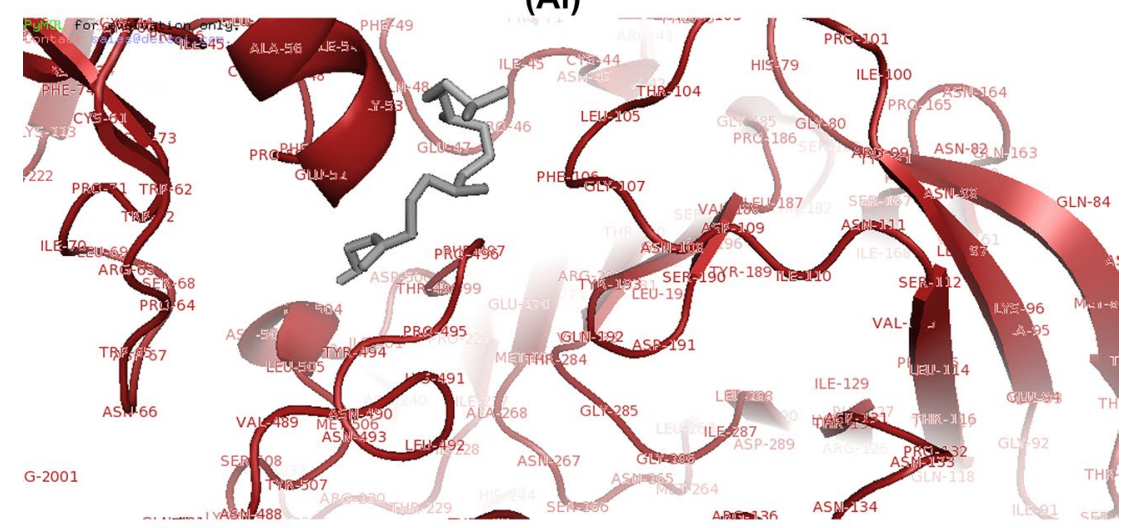

(Aii)

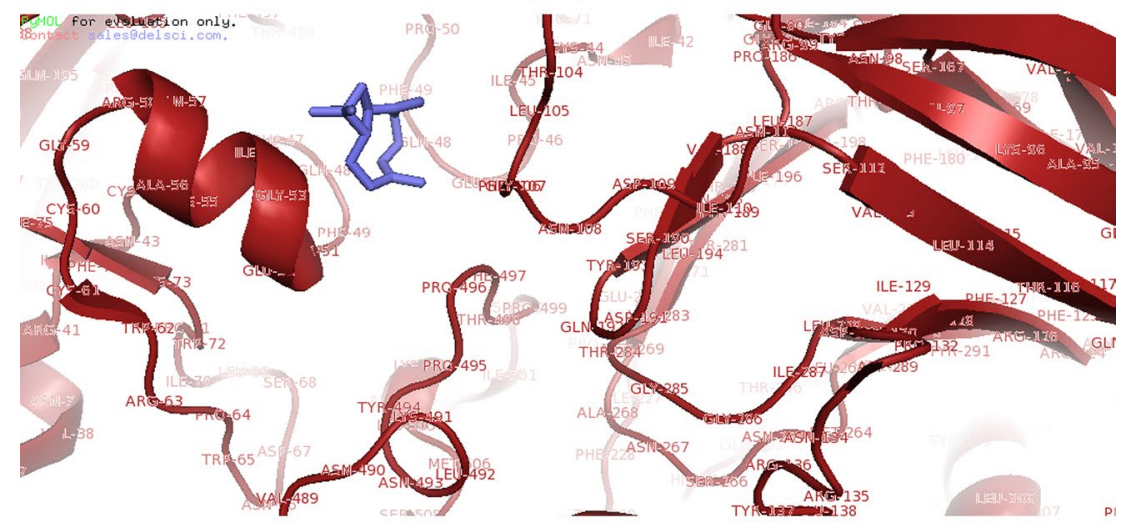

(Aiii)

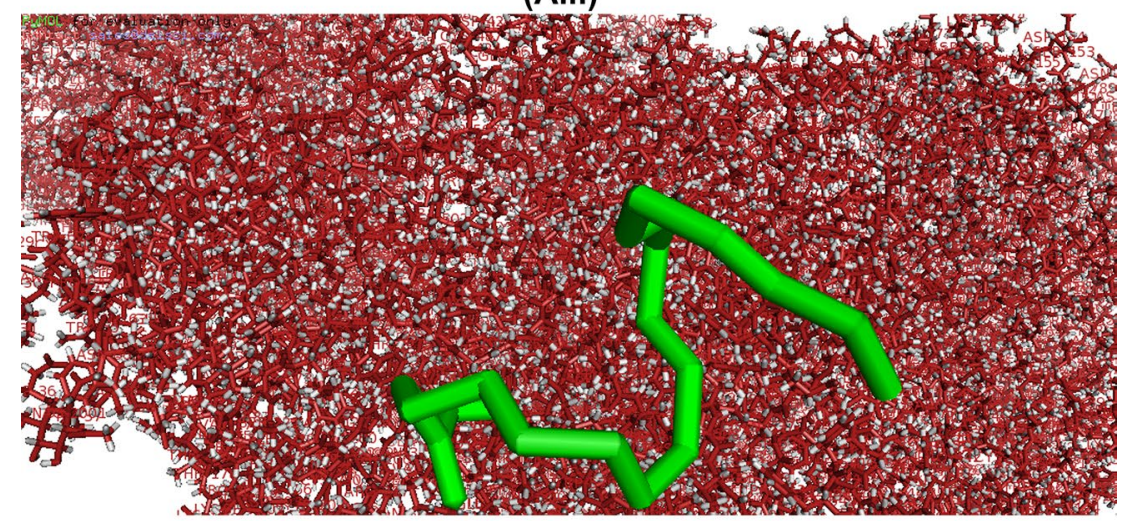

(Aiv) 
Fig. 2 (continued)

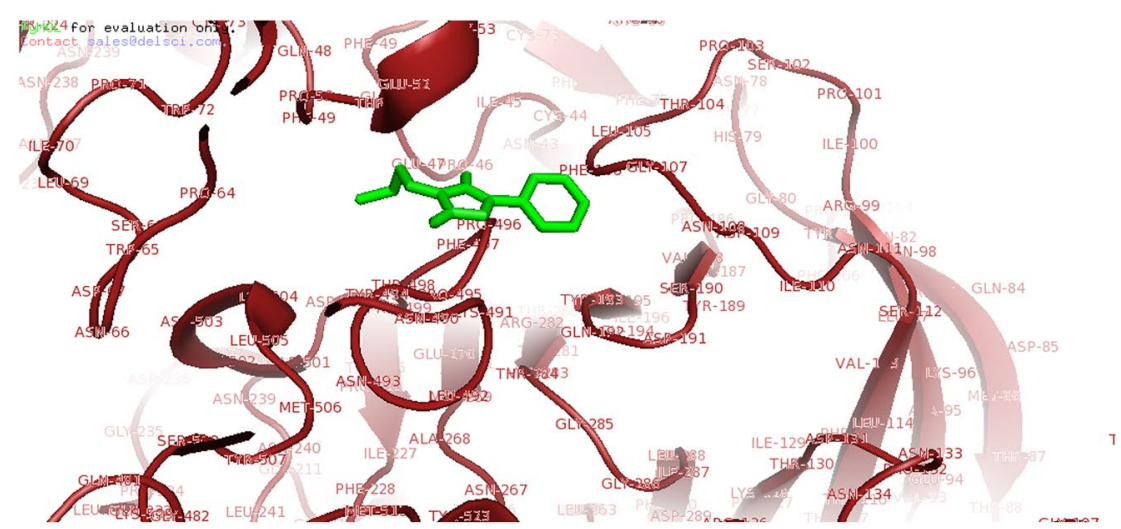

(Av)

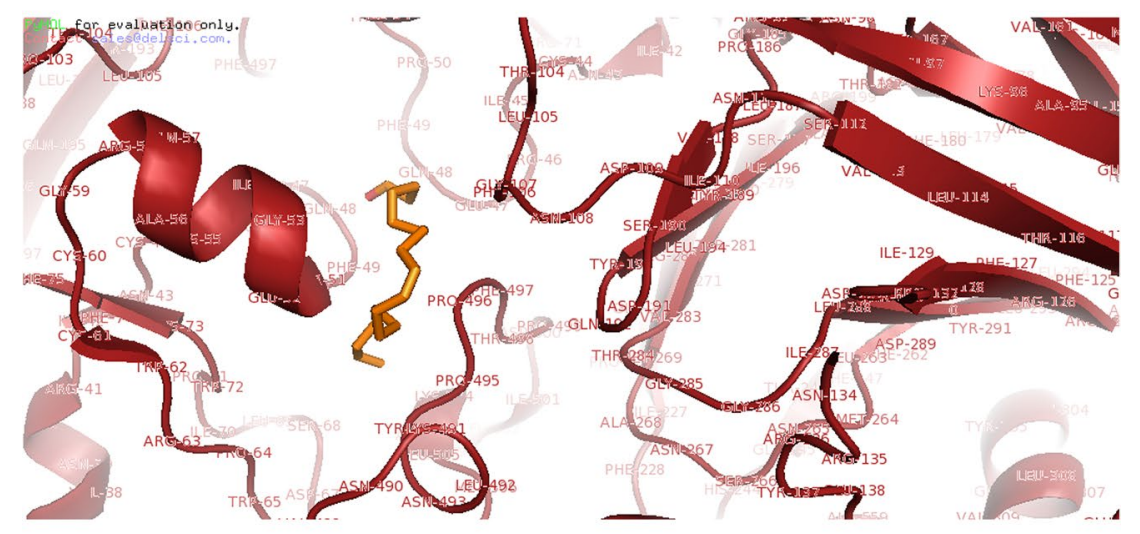

(Avi)

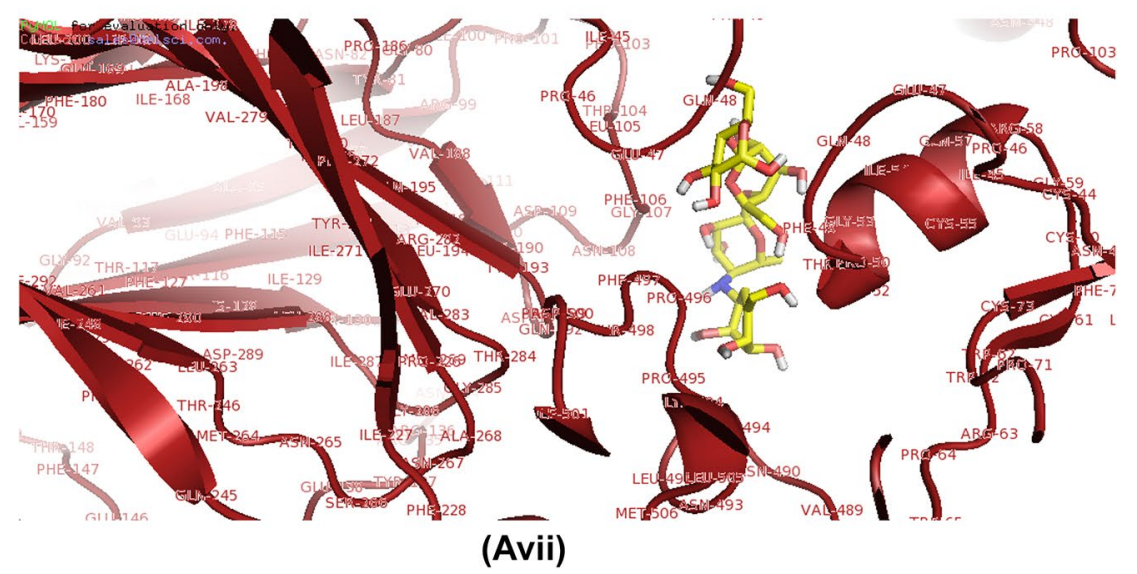

ranges from sucrase to a-amylase and a-glucosidase in decreasing order with CEA and CEP possessing the highest inhibition $62.67 \pm 1.45 \mu \mathrm{g} / \mathrm{mL}$ and $57.67 \pm 0.88 \mu \mathrm{g} / \mathrm{mL}$ respectively for sucrase. Thus, inhibiting these enzymes could play a crucial role in controlling the hyperglycemic condition by limiting glucose absorption in the blood [3, 32]. Thus lowering the postprandial hyperglycemia related responses in diabetes and complements the already established claim by $[19,33]$. However, none of the extracts from plants possessed inhibitory potential than acrabose against the three assessed carbohydrate hydrolyzing enzymes.
Also, molecular mechanistic evaluation of reported compounds of methanol extracts (crude extract of both plants) against the three selected studied enzymes (a-amylase, sucrase-isomaltase and a-glucosidase) carried out revealed the possible interactions between the enzymes and the compounds. The binding energies of the compound-enzyme docked complexes revealed that there could be interactions between the selected compounds and the hydrolases based on the score of the model with least values having the highest affinity [34]. All the compounds docked against a-amylase (1SMD) possessed higher affinity than acarbose except caryophyllene while 
Fig. 3 Molecular docking of compounds with enzyme Ai a-glucosidase (3WY1) and neophytadiene (10446), Aii a-glucosidase (3WY1) and phytol (5280435), Aiii a-glucosidase (3WY1) and caryophyllene (5354499), Aiv a-glucosidase (3WY1) and 9,12,15-octadecatrienoic acid (860), Av a-glucosidase (3WY1) and oxazolone (1712094), Avi a-glucosidase (3WY1) and 9,17-octadecadienal (5365667) and Avii a-glucosidase (3WY1) and acarbose (41774)

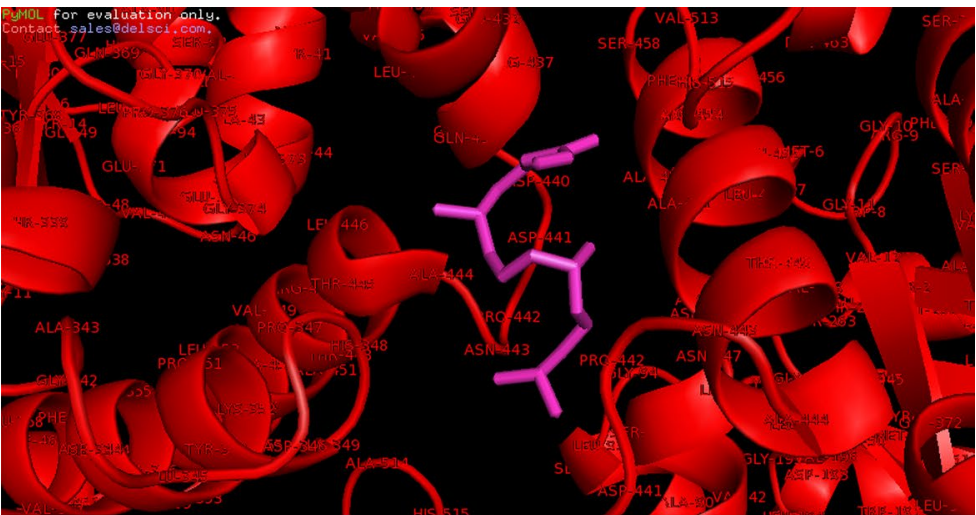

(Ai)

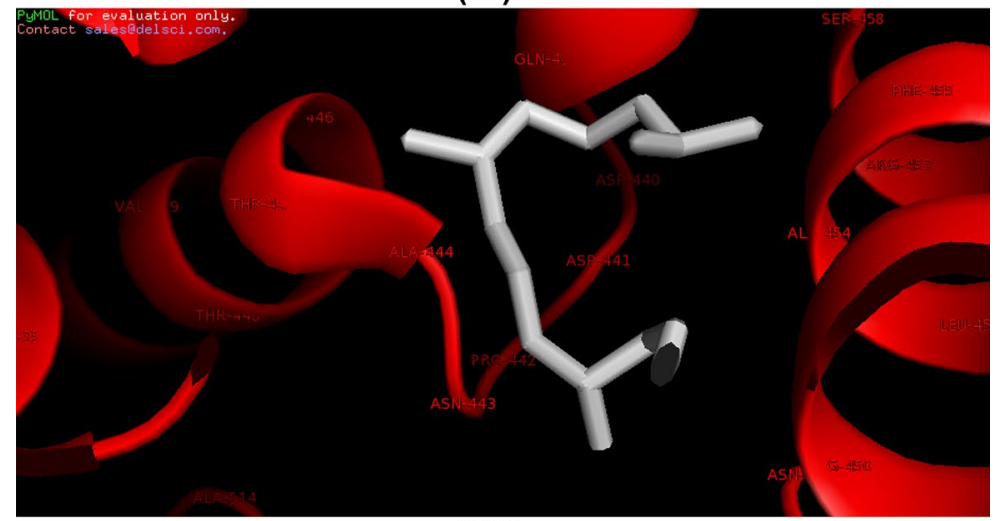

(Aii)

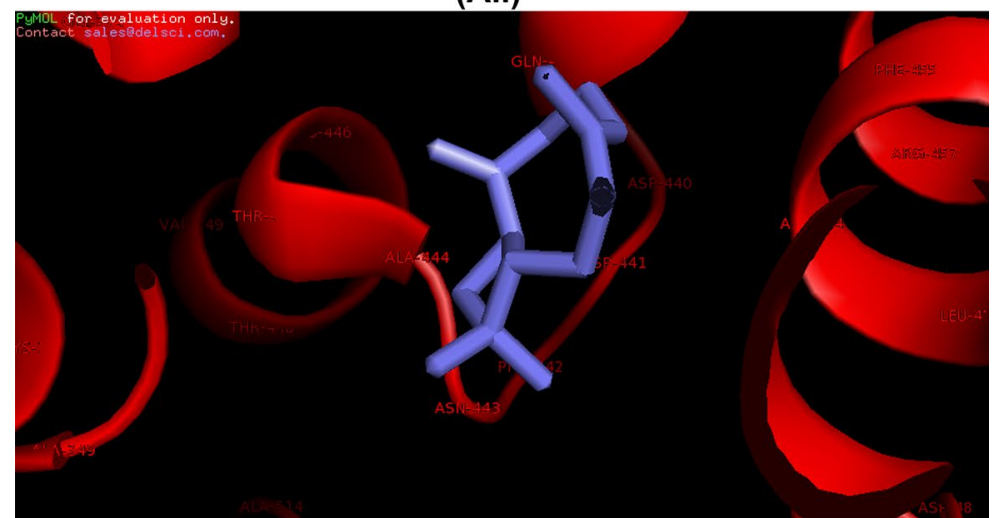

(Aiii)

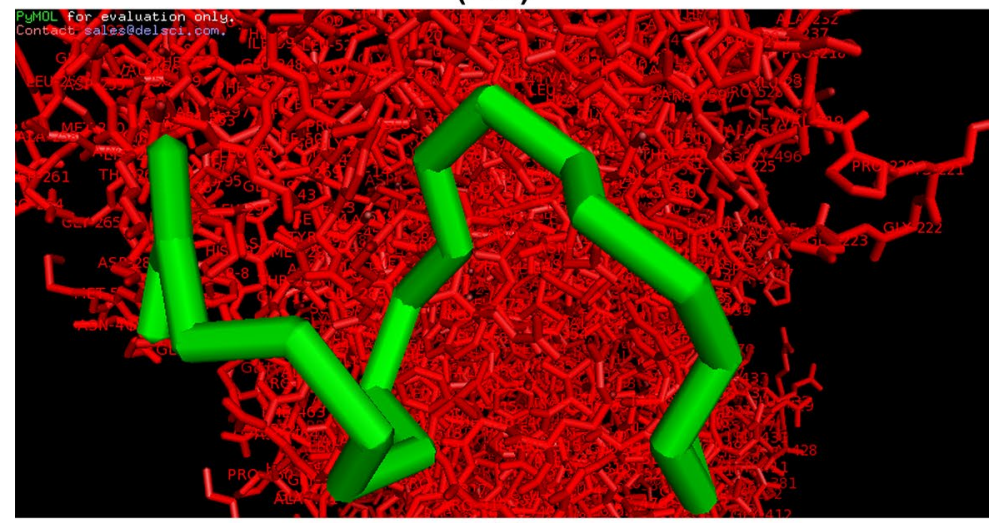

(Aiv) 
Fig. 3 (continued)

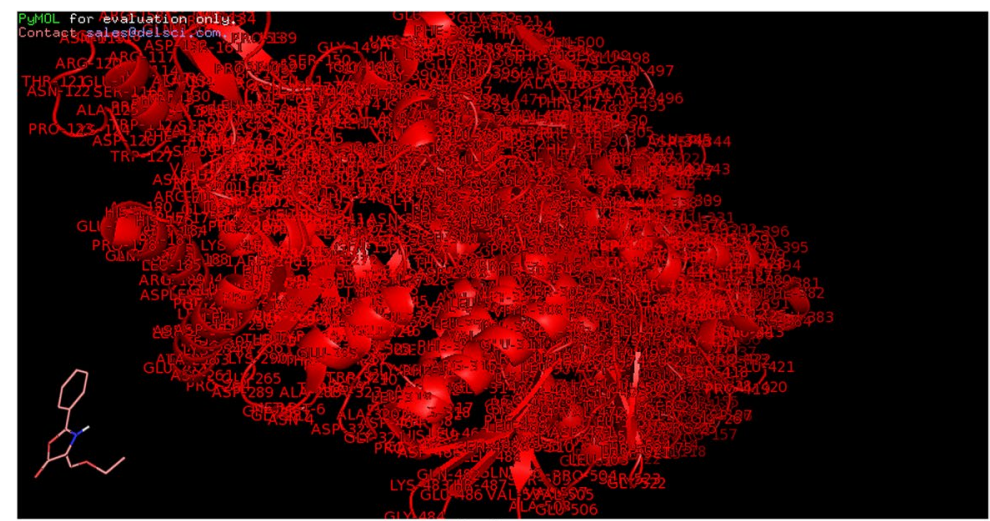

(Av)

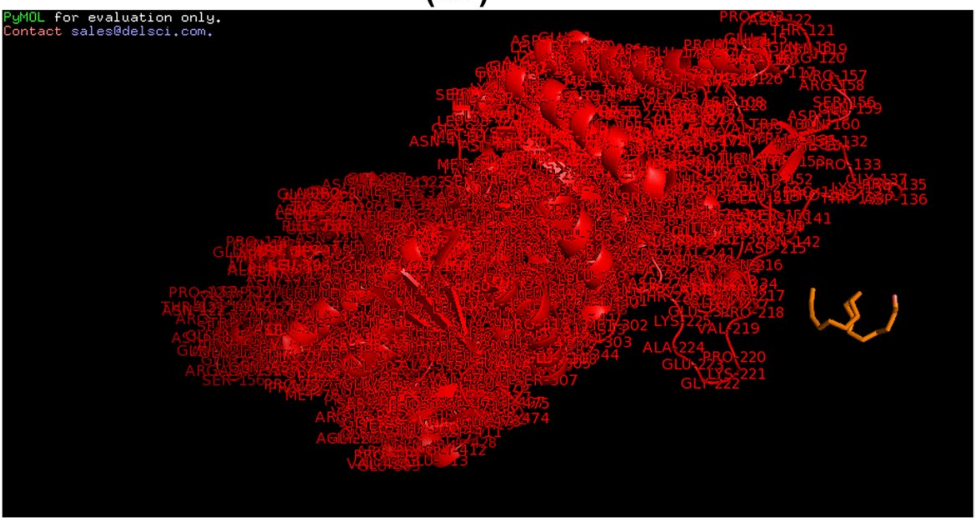

(Avi)

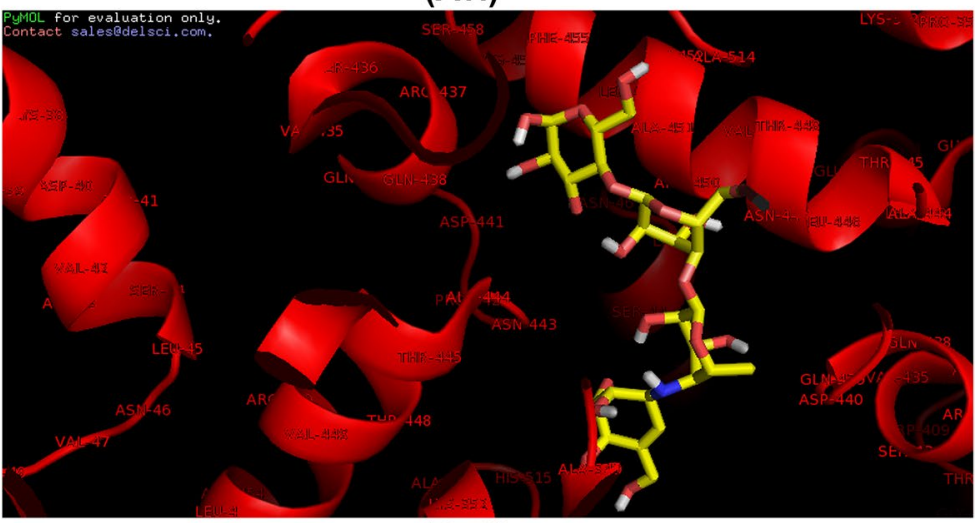

(Avii)

none had higher stability than acarbose against sucraseisomaltase (3LPO) and a-glucosidase (3WY1). Also, phytol (5280435) has the highest biniding energy against the three enzymes compared to other two compounds from $A$. conyzoides and none of the compounds from $P$. amarus docked with a-glucosidase (3WY1) possessed any binding energy. In addition, the amino acid residues at 1SMD active site include Gly-334, Pro-332, Leu-293, Phe-335 while the residue at 3 LPO acive site include Glu-47, Gln-48, Phe-49, Pro-495 and 3WY1 amino acid residues at the active site include Ala-349, Asp-440, Pro-442, Asn-443. The docking and the hyperglycemia studies showed that the methanolic extracts of the plants leaves could contain good inhibitors that could interfere with the selected hydrolases compared to acarbose and limit the rate of glucose absorption in the gut. Though, $P$. amarus leaf methanol extract posed to be more effective than $A$. conyzoides leaf methanol extract as seen in the docking studies which was not obvious in the in vitro hyperglycemia inhibition assays. In addition, the active compounds in plant-based foods are numerous in number and could exhibit synergistic properties in reducing the risk of chronic diseases and maintenance of cell safety. Therefore, interactions between these compounds could result to the increase observed pharmacological activity, and probably the shrub's therapeutic effects as depicted through the superimposition 


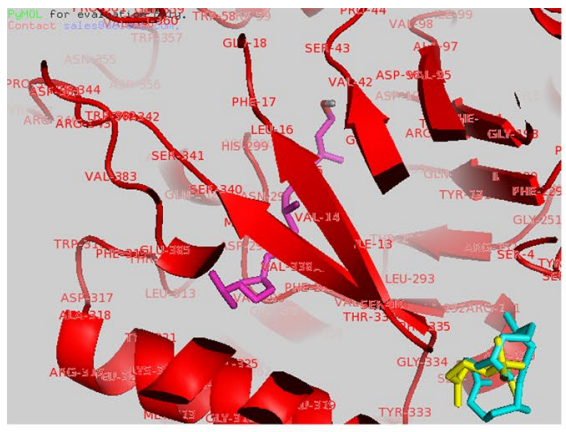

(Ai)

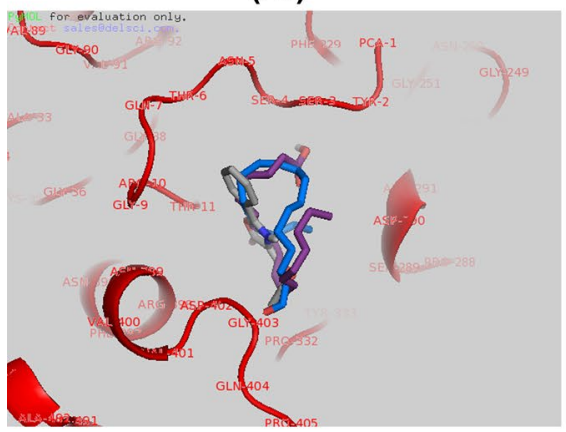

(Aiv)

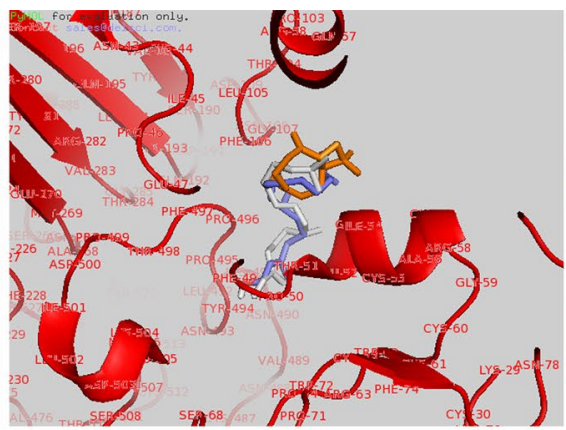

(Aii)

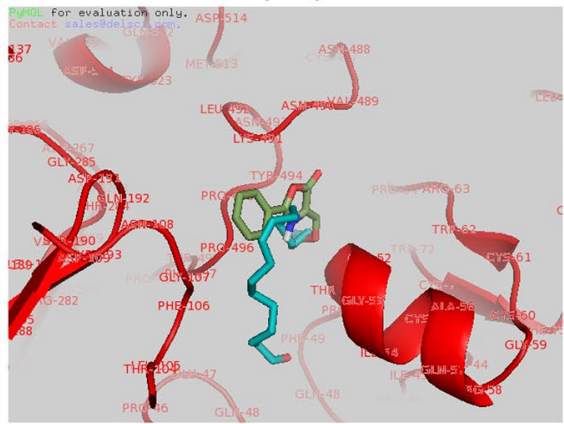

(Av)

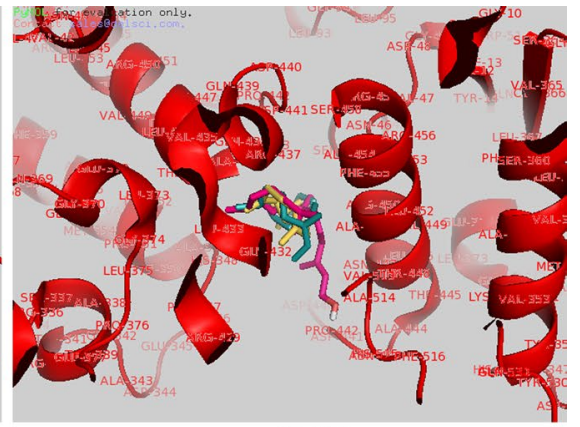

(Aiii)

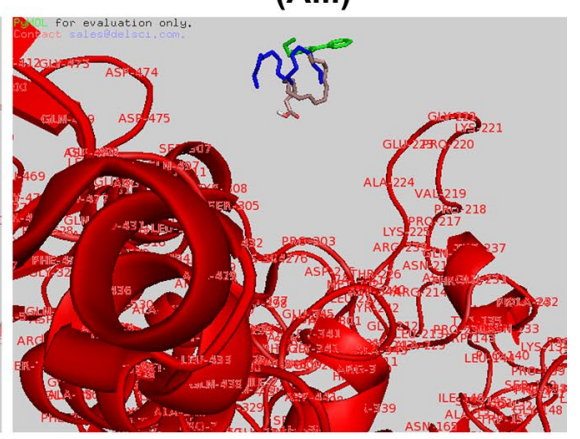

(Avi)
Fig. 4 Superimposition of 3-D structures of neophytadiene (10446), phytol (5280435) and caryophyllene (5354499) from A. conyzoides in the binding site of Ai a-amylase (1SMD), Aii sucrose-isomaltase (3LPO) and Aiii a-glucosidase (3WY1) and superimposition of
3-D structures of 9,12,15-octadecatrienoic acid (860), oxazolone (1712094) and 9,17-octadecadienal (5365667) from $P$. amarus in the binding site of Aiv a-amylase (1SMD), Av sucrose-isomaltase (3LPO) and Avi a-glucosidase (3WY1)
Table 1 Inhibitory potentials of dried leaves of $A$. conyzoides and $P$. amarus on carbohydrate hydrolyzing enzymes

\begin{tabular}{lccc}
\hline Extracts & a-Amylase $(I C 50, \mu \mathrm{g} / \mathrm{mL})$ & Sucrase $(\mathrm{IC} 50, \mu \mathrm{g} / \mathrm{mL})$ & $\begin{array}{c}\text { a-Glucosidase } \\
(I C 50, \mu \mathrm{g} / \mathrm{mL})\end{array}$ \\
\hline AREA & $734.33 \pm 76.02^{\mathrm{a}}$ & $115.10 \pm 18.98^{\mathrm{a}}$ & $177.33 \pm 16.83^{\mathrm{a}}$ \\
$B P E A$ & $244.67 \pm 40.91^{\mathrm{b}}$ & $115.72 \pm 6.14^{\mathrm{a}}$ & $136.00 \pm 11.02^{\mathrm{b}}$ \\
CEA & $78.00 \pm 1.73^{\mathrm{c}}$ & $62.67 \pm 1.45^{\mathrm{b}}$ & $89.67 \pm 3.48^{\mathrm{c}}$ \\
AREP & $373.00 \pm 24.00^{\mathrm{d}}$ & $2075.33 \pm 1474.52^{\mathrm{c}}$ & $158.33 \pm 0.33^{\mathrm{d}}$ \\
BPEP & $257.33 \pm 11.57^{\mathrm{b}}$ & $87.67 \pm 6.23^{\mathrm{d}}$ & $157.00 \pm 2.89^{\mathrm{d}}$ \\
CEP & $77.00 \pm 1.16^{\mathrm{c}}$ & $57.67 \pm 0.88^{\mathrm{e}}$ & $95.33 \pm 2.60^{\mathrm{c}}$ \\
Acarbose & $32.29 \pm 6.82^{\mathrm{f}}$ & $30.72 \pm 1.42^{\mathrm{f}}$ & $33.11 \pm 7.12^{\mathrm{d}}$ \\
\hline
\end{tabular}

Values are expressed as mean of 3 replicates \pm standard deviation of mean. Values with different superscripts within a column are significantly different $(p<0.05)$

$A R E$ aqueous residual extract, BPE butanol partitioned extract, $C E$ methanol crude extract $(A A$. conyzoides, P P. amarus) of the docked compounds inside the binding sites of the enzymes except 3WY1.

Albumin, an abundant plasma proteins, its glycation form glycated albumin (GA) that is ten times more than the glycation of hemoglobin in type II Diabetes mellitus [35]. Human albumin presents $50 \%$ of the normal individual's plasma protein and it is a marker reflects a shortterm glycemic control [36]. In serum, the concentration of all thiols added together is lower than albumin being the most abundant thiol [37]. Glycation is one of the major disruptive spontaneous/non-spontaneous reactions occurring between proteins and reducing sugars that result in secondary complications in diabetic patients. $P$. amarus and $A$. conyzoides methanol extracts were significantly different $(p<0.05)$ from aqueous and butanol extracts on antiglycation property. However, the methanol extract of $P$. amarus exhibited better inhibitory protein glycation. Thus, preventing the deposit of long chain fatty acids and promote drug binding at various stages of diabetes $[38,39]$. Also, the methanol extracts of both herbs 
Table 2 Evaluation of binding energies $(\mathrm{kcal} / \mathrm{mol})$ for the selected molecules from dried leaves of $A$. conyznoides and $P$. amarus

\begin{tabular}{|c|c|c|c|c|c|c|}
\hline Methanolic extracts & Molecules & PubChem CID & $\mathrm{MW}(\mathrm{g} / \mathrm{mol})$ & $\begin{array}{l}\text { a-Amylase } \\
\text { (1SMD) }\end{array}$ & $\begin{array}{l}\text { Sucrase-iso- } \\
\text { maltase (3LPO) }\end{array}$ & $\begin{array}{l}\text { a-Glucosidase } \\
\text { (3WY1) }\end{array}$ \\
\hline \multirow[t]{3}{*}{ A. conyzoides } & Neophytadiene & 10446 & 278.5 & -3.9 & -5.6 & -5.3 \\
\hline & Caryophyllene & 5354499 & 204.35 & 13.1 & -5.3 & -6.2 \\
\hline & Phytol & 5280435 & 296.5 & -5.2 & -5.8 & -6.8 \\
\hline \multirow[t]{3}{*}{ P. amarus } & $9,12,15$-Octadecatrienoate & 860 & 278.4 & -4.3 & -6.4 & 0.0 \\
\hline & Oxazolone & 1712094 & 217.22 & -5.7 & -6.1 & 0.0 \\
\hline & 9,17-Octadecadienal & 5365667 & 264.4 & -4.0 & -5.2 & 0.0 \\
\hline Control & Acarbose & 41774 & 645.6 & 0.7 & -7.0 & -9.8 \\
\hline
\end{tabular}

Table 3 Oxidation of thiol, anti-glycation and $\beta$-amyloid aggregation inhibitory properties of dried leaves of $A$. conyznoides and $P$. amarus

\begin{tabular}{llll}
\hline Extracts & $\begin{array}{l}\text { Inhibition of albumin } \\
\text { glycation (\%) }\end{array}$ & $\begin{array}{l}\text { Inhibition of thiol groups oxidation } \\
\text { (nmol/mg protein) }\end{array}$ & $\begin{array}{l}\text { Inhibition of } \\
\beta \text {-amyloid aggrega- } \\
\text { tion (\%) }\end{array}$ \\
\hline AREA & $48.67 \pm 0.88^{\mathrm{a}}$ & $1.76 \pm 0.06^{\mathrm{a}}$ & $6.67 \pm 0.33^{\mathrm{a}}$ \\
$B P E A$ & $64.33 \pm 0.88^{\mathrm{b}}$ & $2.02 \pm 0.09^{\mathrm{b}}$ & $16.00 \pm 0.58^{\mathrm{b}}$ \\
$C E A$ & $74.67 \pm 1.45^{\mathrm{c}}$ & $2.92 \pm 0.04^{\mathrm{c}}$ & $26.33 \pm 0.33^{\mathrm{c}}$ \\
$A R E P$ & $53.67 \pm 0.33^{\mathrm{d}}$ & $1.87 \pm 0.02^{\mathrm{d}}$ & $9.00 \pm 0.58^{\mathrm{d}}$ \\
$B P E P$ & $69.67 \pm 0.33^{\mathrm{e}}$ & $2.17 \pm 0.06^{\mathrm{b}}$ & $16.67 \pm 0.88^{\mathrm{b}}$ \\
CEP & $77.67 \pm 0.33^{\mathrm{f}}$ & $2.89 \pm 0.13^{\mathrm{c}}$ & $28.00 \pm 0.58^{\mathrm{c}}$ \\
\hline
\end{tabular}

Values are expressed as mean of 3 replicates \pm standard deviation of mean. Values with different superscripts within a column are significantly different $(p<0.05)$

$A R E$ aqueous residual extract, $B P E$ butanol partitioned extract, $C E$ methanol crude extract $(A A$. conyzoides, P P. amarus) could probably inhibit the activation and aggregation of platelet and promote glucose uptake $[40,41]$.

Furthermore, oxidation of macromolecules such as lipids, DNA and proteins by ROS plays an important role in diabetes, cardiovascular disease and other diseases relating to aging like inflammation, cancer. Findings from epidemiology and experiment as well as clinic provided evidence on supportive role of reactive oxygen species (ROS) such as singlet oxygen, superoxide anions $\left(\mathrm{O}_{2}\right)$, hydrogen peroxide $\left(\mathrm{H}_{2} \mathrm{O}_{2}\right)$, and hydroxyl radical $(\mathrm{OH})$ in the etiology of diabetes, cardiovascular diseases, aging etc. [42]. No significant difference between the methanol extracts of the plants as well as the butanol extracts while a significant difference is observed among the three solvents with aqueous extract possessing poor thiol protein protection activity and a fair active of thiol protein protection is observed for butanol extracts of both plants. The high concentration of thiol proteins methanol extracts indicates high potency for the methanol extracts of the plants and could help to reduce the effect of oxidative damage on the sulphydryl group thus protecting the human body from lipid peroxidation that causes cardiovascular disease, a secondary complication of diabetes.

To substantiate the glycation inhibition findings, the inhibition of $\beta$-amyloid fibril formation in glycated albumin was carried out since glycation has been reported by Emendato et al. [43] to increase the level of amyloid cross $\beta$ structure, thus aggravating the cytotoxicities of protein aggregation and in general hyperglycaemia.

\section{Conclusion}

In an attempt to search for a novel phytomedicine for the prevention of secondary complications such as neuropathy, nephropathy, retinopathy etc. arising from diabetes, anti-amyloid aggregation potential of $P$. amarus and $A$. conyzoides extracts using different solvents were evaluated. The result of the present study showed that $P$. amarus exhibited stronger inhibitory potential in all three solvents against amyloid formation when compared with $A$. conyzoides fibrillation-inhibiting potential except with butanol extracts where there is no significant difference. Although $P$. amarus and $A$. conyzoides may be suggested as a potential therapeutic drug for prevention and treatment of secondary complications arising from DM, bioactive compounds of methanol extract of $P$. amarus could probably prevent secondary complications in diabetes compared to $A$. conyzoides methanol extract based on the results obtained from the docking studies and 
the biochemical estimations carried out by the present researchers. However, there is a need to carry out further investigations on other reported compounds in the plant with the help of the in silico approach to generate more effective and potential drug through ligand-based drug designing approaches.

\section{Compliance with ethical standards}

Conflict of interest The authors declared that they have no conflict of interest.

\section{References}

1. Tupe RS, Kemse NG, Khaire AA, Shaikh SA (2017) Attenuation of glycation-induced multiple protein modifications by Indian antidiabetic plant extracts. Pharm Biol 55(1):68-75. https://doi. org/10.1080/13880209.2016.1228683

2. American Diabetes Association (2012) Diagnosis and classification of diabetes mellitus. Diabetes Care 35:S64-S71

3. Li W, Sun YN, Yan XT, Yang SY, Jo SH, Kwon YI, Kim YH (2014) Rat intestinal sucrase and glucosidase inhibitory activities of isocoumarin and flavonoids from the Zanthoxylum schinifolium stems. Bull Korean Chem Soc 35(1):316-318. https://doi.org/10.5012/ bkcs.2014.35.1.316

4. Breuer HW (2003) Review of acarbose therapeutic strategies in the long-term treatment and in the prevention of type 2 diabetes. Int J Clin Pharmacol Ther 41:421-440

5. Mohamed EAH, Siddiqui MJA, Ang LF, Sadikun A, Chan SH, Tan SC, Asmawi MZ, Yam MF (2012) Potent a-glucosidase and a-amylase inhibitory activities of standardized $50 \%$ ethanolic extracts and sinensetin from Orthosiphon stamineus Benth as anti-diabetic mechanism. BMC Complement Altern Med 12(1):176. https://doi.org/10.1186/1472-6882-12-176

6. Nijpels G, Boorsma W, Dekker J, Kostense P, Bouter L, Heine R (2008) A study of the effects of acarbose on glucose metabolism in patients predisposed to developing diabetes: the Dutch acarbose intervention study in persons with impaired glucose tolerance (DAISI). Diabetes/Metab Res Rev 24:611-616

7. Singh $P$, Jayaramaiah $R H$, Agawane $S B$, Vannuruswamy $G$, Korwar AM, Anand A, Dhaygude VS, Shaikh ML, Joshi RS, Boppana R, Kulkarni MJ (2016) Potential dual role of eugenol in inhibiting advanced glycation end products in diabetes: proteomic and mechanistic insights. Sci Rep 6:18798. https://doi.org/10.1038/ srep 18798

8. Kaewnarin K, Rakariyatham N (2017) Inhibitory effects of phenolic compounds in Ocimum sanctum extract on the a-glucosidase activity and the formation of advanced glycation endproducts. Chiang Mai J Sci 44(1):203-214

9. Pashikanti S, de Alba DR, Boissonneault GA, Cervantes-Laurean D (2010) Rutin metabolites: novel inhibitors of nonoxidative advanced glycation end products. Free Radic Biol Med 48(5):656-663. https://doi.org/10.1016/j.freeradbio med.2009.11.019

10. Ates I, Ozkayar N, Topcuoglu C, Dede F (2015) Relationship between oxidative stress parameters and asymptomatic organ damage in hypertensive patients without diabetes mellitus. Scand Cardiovasc J 49(5):249-256. https://doi. org/10.3109/14017431
11. Brownlee M (2005) The pathobiology of diabetic complications: a unifying mechanism. Diabetes 54:1615-1625

12. Kaneto H, Katakami N, Matsuhisa M, Matsuoka T (2010) Role of reactive oxygen species in the progression of type 2 diabetes and atherosclerosis. Mediat Inflamm 2010:453892

13. Sies $H$ (2015) Oxidative stress: a concept in redox biology and medicine. Redox Biol 4:180-183. https://doi.org/10.1016/j. redox.2015.01.002

14. Cremers CM, Jakob U (2013) Oxidant sensing by reversible disulfide bond formation. J Biol Chem 288(37):26489-26496. https://doi.org/10.1074/jbc.R113.462929

15. Erel O, Neselioglu S (2014) A novel and automated assay for thiol/disulphide homeostasis. Clin Biochem 47(18):326-332. https://doi.org/10.1016/j.clinbiochem.2014.09.026

16. Olga B, Eija V, Kurt V (2003) Antioxidants, oxidative damage and oxygen deprivation stress: a review. Ann Bot 91:179-194

17. Dahlqvist A (1964) Methods of assay of instetinal disacharidases. Anal Biochem 7:1825

18. Bernfeld P (1955) Amylase, $a$ and $\beta$. In: Colowick SP, Kaplan NO (eds) Methods in enzymology. Academic Press, New York, pp 149-158

19. Kim YM, Jeong YK, Wang MH, Lee YH, Rhee HI (2005) Inhibitory effect of pine extract on alpha-glucosidase activity and postprandial hyperglycaemia. Nutrition 21:756-761

20. Honda M, Hara Y (1993) Inhibition of rat small intestinal sucrase and a-glucosidase activities by tea polyphenols. Biosci Biotechnol Biochem 57:123-124

21. Safari M, Sheikh N, Kashani KM (2010) Study on the effect of vitamin $C$ on the in vitro albumin glycation reaction. Iran J Pharm Res 4:275-279

22. Furth AJ (1988) Methods for assaying nonenzymatic glycosylation. Anal Biochem 175:347-360

23. Ellman GL (1959) Tissue sulfhydryl groups. Arch Biochem Biophys $82: 70-77$

24. Klunk WE, Jacob RF, Mason RP (1999) Quantifying amyloid by Congo red spectral shift assay. Methods Enzymol 309:285-305

25. Ilondu EM, Ojeifo IM, Emosairue SO (2014) Evaluation of antifungal properties of Ageratum conyzoides, Spilanthes filicaulis and Tithonia diversifolia leaf extracts and search for their compounds using gas chromatography-mass spectrum. ARPN J Agric Biol Sci 9(11):375-384

26. Prajapati R, Roy S, Mishra S, Raza SK, Thakur LK (2014) Formulation development, standardization and antimicrobial activity of Ageratum conyzoides extracts and their formulation. Int J Pharm Pharm Sci 6(suppl 2):369-374

27. Pandurangan S, Mohan A, Sethuramali B, Ramalingam S (2015) GC-MS analysis of methanolic extract of Phyllanthus amarus leaves collected from Salem Region. Asian J Pharmacol Toxicol 3(10):54-59

28. Kavishankar G, Lakshmidevi N (2015) Antidiabetic an antioxidant potency evaluation of different fractions obtained from Cucumis prophetarum fruit. J Pharm Biol 53(5):689-694

29. Manisha M, Priyanjali D, Jayant L, Saroj G, Thomas PAD (2007) Indian herbs and herbal drugs used for the treatment of diabetes. J Clin Biochem Nutr 40(3):163-173

30. Verma PK, Raina R, Sultana M, Prawez S, Jamwal N (2013) Hepatoprotective mechanisms of Ageratum conyzoides L. on oxidative damage induced by acetaminophen in Wistar rats. Free Radic Antioxid 3(2):73-76. https://doi.org/10.1016/j. fra.2013.05.009

31. Saravanan R, Saradhai P, Rani S (2012) Effect of Phyllanthus amarus extract on SphH gene of Leptospira autumnalis studied by an in-house PCR. Indian J Appl Microbiol 15:40-45

32. Oboh G, Isaac AT, Akinyemi AJ, Ajani RA (2014) Inhibition of key enzymes linked to type 2 diabetes and sodium nitroprusside induced lipid peroxidation in rats' pancreas by phenolic 
extracts of avocado pear leaves and fruit. Int J Biomed Sci 10(3):208-216

33. Sasidharan I, Sundaresan A, Nisha VM, Kirishna MS, Raghu KG, Jayamurthy P (2012) Inhibitory effect of Terminalia chebula Retz. fruit extracts on digestive enzyme related to diabetes and oxidative stress. J Enzyme Inhib Med Chem 12(4):578-586

34. Cosconati S, Forli S, Perryman AL, Harris R, Goodsell DS, Olson AJ (2010) Virtual screening with AutoDock: theory and practice. Expert Opin Drug Discov 5(6):597-607

35. Tahara Y, Shima K (1995) Kinetics of HbA1c, glycated albumin, and fructosamine and analysis of their weight functions against preceding plasma glucose level. Diabetes Care 18:440-447. https://doi.org/10.2337/diacare.18.4.440

36. Yoon H, Lee Y, Kim K, Kim S, Kang E, Cha B, Lee H, Lee B (2015) Glycated albumin levels in patients with type 2 diabetes increase relative to $\mathrm{HbA1C}$ with time. Biomed Res Int. https:// doi.org/10.1155/2015/576306

37. Turell L, Radi R, Alvarez B (2013) The thiol pool in human plasma: the central contribution of albumin to redox processes. Free Radic Biol Med 65:244-253

38. Hasan NA (2009) Effects of trace elements on albumin and lipoprotein glycation in diabetic retinopathy. Saudi Med J 30:1263-1271

39. Barnaby OS, Cerny RL, Clarke W, Hage DS (2011) Comparison of modification sites formed on human serum albumin at various stages of glycation. Clin Chim Acta 412:277-285
40. Rubenstein DA, Yin W (2009) Glycated albumin modulates platelet susceptibility to flow induced activation and aggregation. Platelets 20:206-215

41. Unoki $H$, Bujo $H$, Yamagishi $S$, Takeuchi M, Imaizumi T, Saito $Y$ (2007) Advanced glycation end products attenuate cellular insulin sensitivity by increasing the generation of intracellular reactive oxygen species in adipocytes. Diabetes Res Clin Pract 76:236-244

42. Surveswaran S, Cai Y, Corke H, Sun M (2007) Systematic evaluation of natural phenolic antioxidants from 133 Indian medicinal plants. Food Chem 102:938-953

43. Emendato A, Milordini G, Zacco E, Sicorello A, Piaz FD, Remo GR, Thorogate R, Picone D, Pastore A (2018) Glycation affects fibril formation of $A \beta$ peptides. J Biol Chem 293(34):13100-13111. https://doi.org/10.1074/jbc.RA118.002275

Publisher's Note Springer Nature remains neutral with regard to jurisdictional claims in published maps and institutional affiliations. 